\title{
A atenção básica ao idoso que vive na comunidade
}

\author{
Primary care for the elderly living in the community
}

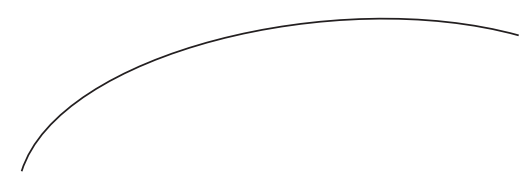

Este número da RBGG (v. 16, n. 4) não é um número temático. Ou, pelo menos, não foi intenção da editoria realizar um número temático. No entanto, ao final do processo de seleção dos artigos veio uma constatação: a ênfase deste número é o idoso que vive na comunidade e recebe a atenção básica em saúde.

Não podemos dizer que é por acaso que tantos artigos sobre esse tema tenham nos chegado nos últimos meses. O fato é que, finalmente, os pesquisadores e profissionais que atuam na atenção básica e fazem pesquisa descobriram a importância, a relevância e a necessidade de se produzir conhecimento sobre o idoso que vive na comunidade.

Em 16 artigos originais, temos os seguintes temas: o bem-estar de idosos cuidadores e não cuidadores (Unicamp, SP); validação de uma técnica de mensuração do percentual de gordura (Universidade Federal de Alagoas, AL); Problemas relacionados aos medicamentos em idosos fragilizados (Universidade Federal de Juiz de Fora, MG); percepções de docentes da rede básica de educação sobre o processo de envelhecimento (Universidade Federal do Pampa, RS); efeitos de um programa de jogos pré-desportivos nos aspectos psicobiológicos de idosas (Unifesp, SP); capacidade funcional de idosos atendidos pela Estratégia Saúde da Família (UnB, Brasília); bandicap auditivo antes e após uso do aparelho auditivo (Universidade Federal do Paraná, PR); atuação do farmacêutico em equipe multiprofissional com ênfase no cuidado ao idoso hospitalizado (Universidade Federal de Minas Gerais, MG); uso da plataforma balance board como recurso fisioterápico em idosos (Universidade Federal do Paraná, PR); estado nutricional e prevalência de doenças crônicas em idosos (Centro Universitário Univates, Lageado, RS); Programa de Educação Popular em Saúde: hábitos de vida e sintomas depressivos em idosos (Unicamp, SP); espiritualidade entre idosos mais velhos (Universidade Federal de Santa Catarina, SC); força muscular e qualidade de vida em idosas (Universidade Federal do Maranhão, MA); equilíbrio estático entre jovens, adultos e idosos (Unesp, SP); grupos de convivência como suporte ao idoso (Universidade de Santa Cruz do Sul, RS); oficinas educativas sobre HIV/Aids para idosos (Centro Universitário La Salle, Canoas, RS).

Também temos três artigos de revisão de literatura sobre os seguintes temas: análise metodológica do treinamento de força como estratégia de controle da pressão arterial em idosos (Universidade Gama Filho, MS e USP, SP); quedas em idosos não institucionalizados (PUC-Goiás); e a incontinência urinária em idosos institucionalizados (Universidade Federal do Rio Grande do Norte, RN). 
Sabemos que a população de 60 anos ou mais é a principal usuária proporcional de consultas médicas e internações, apresentando maior número de doenças crônicas. Os gastos com saúde serão progressivamente maiores com o envelhecimento populacional. Porém, grandes gastos não garantem a melhoria da qualidade de vida dos idosos, sendo necessário trabalhar para a mudança nos princípios que regem a atenção à saúde do idoso. A atenção básica é fundamental nesse processo de transformação.

Os artigos publicados neste número da RBGG reforçam a necessidade de garantir uma via de entrada única ao sistema, através da atenção básica, e que a assistência seja organizada de acordo com os graus de dependência, verificados a partir da capacidade funcional e do risco de fragilidade existente.

Boa leitura! 